\title{
An Improved Method For The Protection Of Carboxylic Acids As 1,1-Dimethylallyl Esters
}

\author{
Abstract

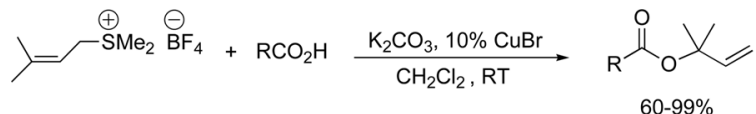 \\ 1,1-Dimethylallyl (DMA) esters of various $\mathrm{N}$-protected amino acids have been synthesized using \\ prenyldimethylsulfonium tetrafluroborate, a reagent that can be readily made and stored, in \\ conjunction with catalytic $\mathrm{CuBr}$. These reactions were complete within several hours and afforded \\ DMA esters in high yields. As has been previously shown in our group, DMA esters represent a \\ palladium-labile proctecting group for carboxylic acids that resists nucleophilic attack as a tert-butyl \\ ester would.
}

In an earlier publication, we reported a general approach for the protection of carboxylic acids as their 1,1-dimethylallyl (DMA) esters (Scheme 1 ), ${ }^{1}$ which can serve as an alternative to tert-butyl esters for the protection of acid-sensitive substrates when resistance to nucleophilic attack on the ester carbonyl is needed. In our previous work, the synthesis of DMA esters was performed in two steps: formation of 1,1-dimethylpropargyl ester intermediates and subsequent partial hydrogenation to afford the desired DMA esters.

In pursuit of a one-pot method for synthesizing this potentially useful protecting group, we turned to the earlier work of Julia and co-workers (Scheme 2), who had reported that the alkylation of potassium benzoate with allylic sulfonium salts could be catalyzed by copper (I) salts to afford a reversed regioselectivity of addition. 2,3

Julia found that, whereas the uncatalyzed reaction took place essentially without significant allylic rearrangement, copper (I) catalysis dramatically changes the regioselectivity as shown in Scheme 2.2,4,5 Julia explained this remarkable reversal of regioselectivity by the formation of a reactive $\pi$-allyl or rapidly equilibrating $\sigma$-allyl copper intermediate that would undergo preferential nucelophilic attack at its most substituted end. ${ }^{4,5}$ Although the replacement of potassium benzoate with other nucleophiles was explored, the use of this reaction with other carboxylate salts wasn't explored. We therefore decided to re-examine this reaction with our previously reported substrates for DMA protection to assay this reaction for both generality and convenience of use. Herein are reported the results of our study.

Prompted by Julia's findings, we sought to explore the generality of this reaction using a variety of carboxylic acids. Prenyldimethylsulfonium tetrafluoroborate (1) was prepared by reaction of dimethyl sulfide with prenyl alcohol in the presence of tetrafluoroboric acid (Scheme 3). Although 1 was stable for several months at $-20^{\circ} \mathrm{C}$ as judged by NMR, it was found that freshly prepared material afforded the best yields in reactions with carboxylic acids.

Corresponding Author. Tel.: +765-494-0132; fax: +765-494-0239, lipton@ @urdue.edu.

Department of Chemistry and Cancer Center, Purdue University, 560 Oval Drive, West Lafayette, IN 47907-2084 
With $\mathbf{1}$ in hand, we first esterified benzoic acid to verify the ability of $\mathbf{1}$ and catalytic $\mathrm{CuBr}$ to regioselectively alkylate carboxylic acids. When benzoic acid was reacted with $\mathbf{1}$ in the presence of potassium carbonate and catalytic copper bromide in dichloromethane at ambient temperature, it furnished the corresponding 1,1-dimethylallyl ester (4) in quantitative yield with no need for purification. The high yield and excellent regioselectivity encouraged us to study the generality of this reaction by investigating the reaction of several different $\mathrm{N}$ protected amino acids (Table 1) used in our previous study. ${ }^{1}$ It was found that 1 reacts in high yield and regioselectively with the amino acids studied regardless of the functionality present. Generally, the reactions were completed within 8-16 hours and in most cases good yields were obtained. Of all the cases examined, the lowest yield obtained was with Fmoc-glycine (7i), which most likely results from loss of material during workup and isolation. When the Fmoc derivatives of Cys, His and Arg (7k-m), which have highly nucleophilic sidechains, were subjected to the reaction conditions, it was found that 4 equivalents of $\mathbf{1}$ were required to obtain a high yield of DMA ester. In most cases, ${ }^{1} \mathrm{H}$ NMR analysis of the crude product after workup showed essentially pure DMA ester, indicating near quantitative yields in most cases; however, the yields reported in Table 1 are those after purification by flash column chromatography. In all cases, it was found that commercial $\mathrm{CuBr}$ was suitable for use in this reaction with no need for further purification.

In our previous paper, we showed that both the Fmoc group and the DMA ester are orthogonal protecting groups and can be removed selectively in the presence of each other. Moreover, DMA deprotection using catalytic $\mathrm{Pd}(0)$ and $N$-methylmorpholine proceeded in high (82-90\%) yield and was compatible with $t$-butyl protection of various amino acid sidechains. ${ }^{1}$

In summary, the use of prenyldimethylsulfonium tetrafluoroborate (1) to convert carboxylic acids to 1,1-dimethylallyl (DMA) esters has been shown to be general and convenient and afford products in good-to-excellent yields. The reagent $\mathbf{1}$ is conveniently prepared from prenyl alcohol and can be stored for extended periods of time. DMA esters themselves are useful alternatives to tert-butyl esters in cases where an allyl ester would be too susceptible to nucleophilic attack and the system is acid-sensitive. ${ }^{1}$ It is anticipated that this improved method for the preparation of DMA esters will facilitate their use in organic synthesis.

\section{Experimental Section}

\section{Dimethyl-(3-methyl-2-butenyl)-sulfonium tetrafluoroborate (1). $\mathbf{4}$}

To a cooled solution $\left(-20^{\circ} \mathrm{C}\right)$ of 3-methyl-2-buten-1-ol ( $\left.0.86 \mathrm{~g}, 0.010 \mathrm{~mol}\right)$ in anhydrous dichloromethane $(10 \mathrm{~mL})$, dimethylsulfide $(6.2 \mathrm{~g}, 0.10 \mathrm{~mol})$ was added. After 10 minutes, $\mathrm{HBF}_{4}(54 \mathrm{wt} \%$ in diethyl ether, $0.64 \mathrm{~mL}, 0.010 \mathrm{~mol}$ ) was added and the mixture was stirred for $6 \mathrm{~h}$ at $0{ }^{\circ} \mathrm{C}$ followed by $14 \mathrm{~h}$ at room temperature. The solvent was removed under vacuum and the brown liquid residue was diluted with acetonitrile $(30 \mathrm{~mL})$. The resultant solution was washed with saturated sodium-bicarbonate until it reached neutral $\mathrm{pH}$, and the organic layer dried over anhydrous sodium sulfate. After removal of the solvent under reduced pressure, the desired product was obtained as a pale brown solid in $98 \%$ yield. $\mathrm{mp}=46-48{ }^{\circ} \mathrm{C}$. ${ }^{1} \mathrm{H}-\mathrm{NMR}$ $\left(300 \mathrm{MHz}, \mathrm{CDCl}_{3}\right) \delta 5.35(\mathrm{t}, \mathrm{J}=7.9 \mathrm{~Hz}, 1 \mathrm{H}), 4.11(\mathrm{~d}, \mathrm{~J}=7.6 \mathrm{~Hz}, 2 \mathrm{H}), 2.91(\mathrm{~s}, 6 \mathrm{H}), 1.98(\mathrm{~s}$, $6 \mathrm{H}), 1.92(\mathrm{~s}, 3 \mathrm{H}) .{ }^{13} \mathrm{C}$ NMR $\left(75 \mathrm{MHz}, \mathrm{CD}_{3} \mathrm{CN}\right) \delta 148.1,108.5,40.3,25.1,22.8,17.8$. IR (neat) 3645.7, 3033.2, 2988.9, 2937.2, 1664.5, 1435.9, 1384.3, 1343.7, 1288.4, 1056.2, 927.1, 846.0, 728.1, $517.9 \mathrm{~cm}^{-1}$. HRMS (ESI): Calcd for $\mathrm{C}_{7} \mathrm{H}_{15} \mathrm{SBF}\left(\mathrm{M}^{+}\right)$131.0894, found 131.0892.

\section{General procedure for the synthesis of 1,1-dimethylallyl esters (4, 8a-p)}

A solution of $\mathbf{1}(218 \mathrm{mg}, 1.00 \mathrm{mmol})$ in dichloromethane $(3 \mathrm{ml})$ was added to a stirred suspension of carboxylic acid $(1.00 \mathrm{mmol})$, potassium carbonate $(138 \mathrm{mg}, 1.00 \mathrm{mmol})$ and $\mathrm{CuBr}(1.4 \mathrm{mg}, 0.010 \mathrm{mmol})$ in dry dichloromethane $(10 \mathrm{ml})$ at $25{ }^{\circ} \mathrm{C}$ under nitrogen 
atmosphere. The mixture was stirred at room temperature until complete as judged by TLC (8-17 h). The mixture was filtered and the filtrate was evaporated under reduced pressure. The crude product was purified by flash column chromatography using ethyl acetate/petroleum ether (1: 9).

\section{Supplementary Material}

Refer to Web version on PubMed Central for supplementary material.

\section{Acknowledgements}

We thank the National Institutes of Health (AI-50888) for support of this work.

\section{References}

1. Sedighi M, Lipton MA. Org Lett 2005;7:1473. [PubMed: 15816730]

2. Badet B, Julia M, Ramirez-Munoz M, Sarrazin A. Tetrahedron 1983;39:3111.

3. Julia M, Mestdagh H, Rolando C. Tetrahedron 1986;42:3841.

4. Gauchet F, Julia M, Mestdagh H, Rolando C. Bull Soc Chim Fr 1987:1036.

5. Gauchet F, Julia M, Mestdagh H, Rolando C. Bull Soc Chim Fr 1990;127:268. 

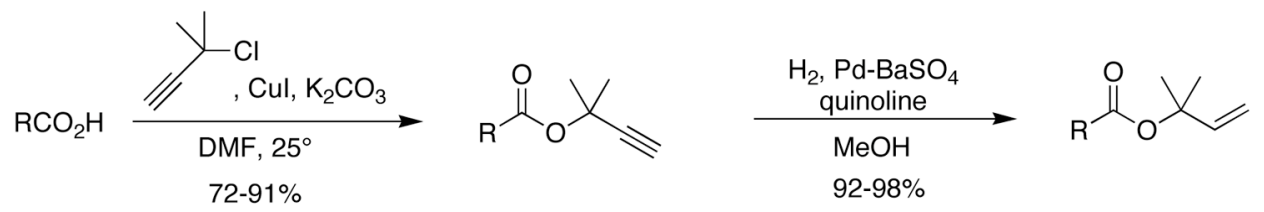

Scheme 1.

Prior synthesis of DMA esters from carboxylic acids. ${ }^{1}$ 


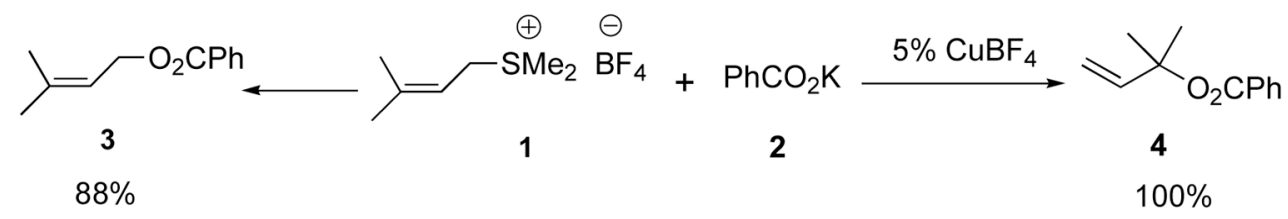

Scheme 2.

Catalyzed and uncatalyzed reactions of allylic sulfonium ions with benzoate. ${ }^{2,3}$ 


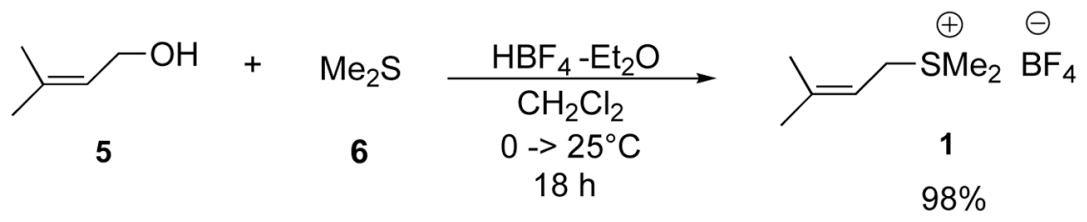

Scheme 3 .

Synthesis of $\mathbf{1}$. 
Table 1

Synthesis of DMA Esters from Carboxylic Acids

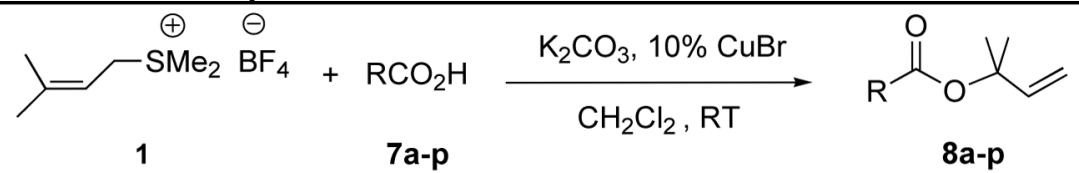

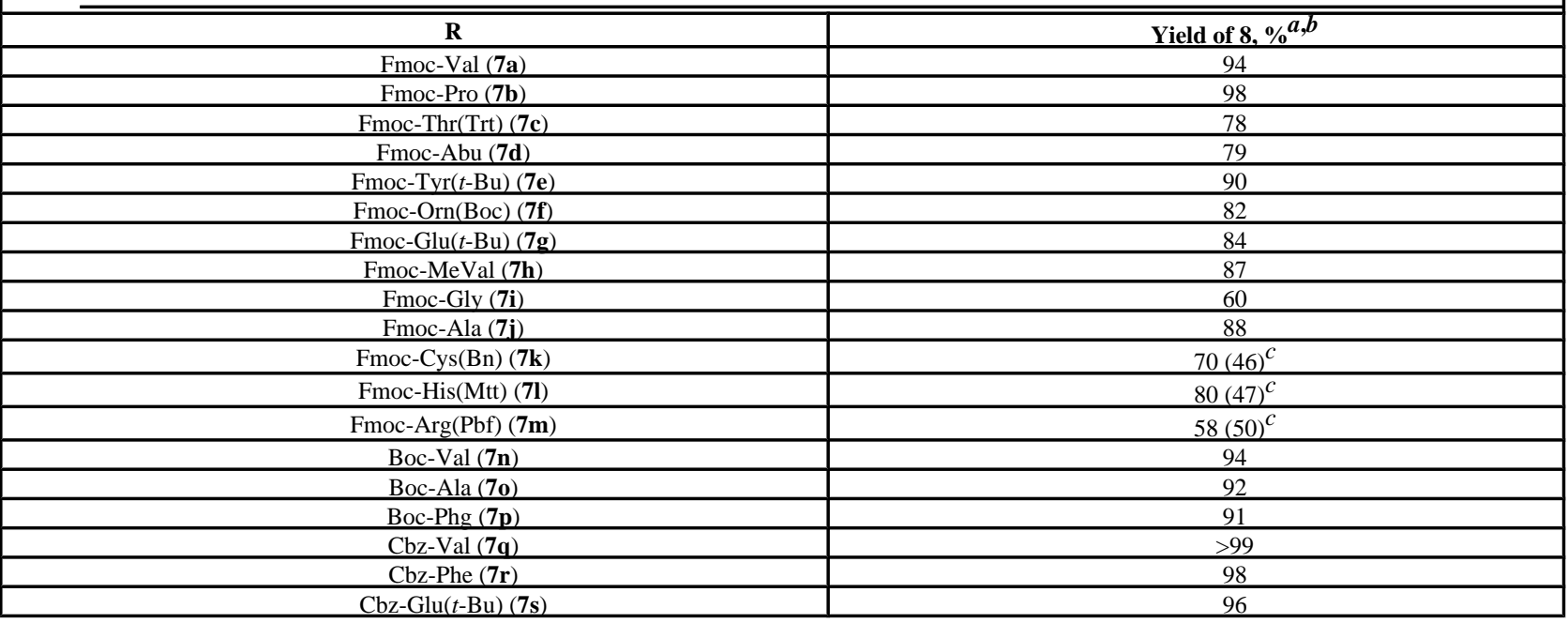

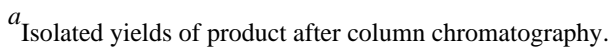

${ }^{b}$ One equivalent of $\mathbf{1}$ used.

${ }^{c}$ Results obtained using four equivalents of $\mathbf{1}$; number in parentheses is the yield using one equivalent of $\mathbf{1}$. 